\title{
The effect of parity on the function of pelvic floor musculature in the long term: cross-sectional study
}

\author{
Daiane Munhoz Mira Bertacini, PT, Ana Carolina Sartorato Beleza, PhD, Patricia Driusso, PhD \\ Department of Physical Therapy, Federal University of São Carlos, São Paulo, Brazil
}

\section{Objective}

Parity is associated with an increased risk of pelvic floor muscle dysfunction. The aim of this study was to evaluate the long-term effects of parity on this musculature.

\section{Methods}

This cross-sectional study was completed at the Department of Physical Therapy, Federal University of São Carlos, Brazil. In total, 143 women participated in the study and were classified into three groups according to parity: nulliparae, primiparae, and secundiparae women. All parous participants had last given birth between 1 and 6 years prior. Pelvic floor muscle function was assessed through unidigital vaginal palpation using the PERFECT scheme, with the contraction grade classified according to the Modified Oxford Scale and through manometry.

\section{Results}

There was no difference in scores on the Modified Oxford Scale (the means and standard deviations were $2.5 \pm 0.8$ in nulliparae women, $2.3 \pm 0.9$ in primiparae women, and $2.2 \pm 0.9$ in secundiparae women; $P=0.482$ ) and manometry findings (the means and standard deviations were $42.3 \pm 22.7$ in nulliparae women, $35.0 \pm 21.8$ in primiparae women, and $33.2 \pm 20.0$ in secundiparae women; $P=0.144$ ) among the assessed groups.

\section{Conclusion}

Parity had no effect, regardless of mode of birth, on the function of pelvic floor muscles and the presence of urinary symptoms, such as long-term urinary incontinence after birth.

Keywords: Muscle strength; Pelvic floor; Parity; Urinary incontinence; Postpartum period

\section{Introduction}

The structures of the pelvic floor (PF), such as muscles, connective tissue, and peripheral nerves, are influenced by hormonal, anatomical, and morphological changes during pregnancy $[1,2]$, contributing to functional and structural modifications to the PF. This may result in long-term dysfunction, such as urinary incontinence (UI) [3]. The growth and increasing weight of the uterus and fetus increase the load on the pelvic floor muscles (PFMs). Moreover, the rise in levels of progesterone and relaxin contributes to a decline in musculature function [1].

In a recent systematic review, it was reported that vaginal delivery was related to a higher risk of long-term (greater than 1 year) stress urinary incontinence (SUI) after birth than a cesarean section [4]. However, the difference between
Received: 2019.12.26. Revised: 2020.03.27. Accepted: 2020.04.12. Corresponding author: Patricia Driusso, $\mathrm{PhD}$

Department of Physical Therapy, Federal University of São Carlos, Washington Luis Highway, SP-310, São Carlos, São Paulo 13565-

905, Brazil

E-mail: patriciadriusso@gmail.com

https://orcid.org/0000-0001-8067-9786

This study was conducted at the Federal University of São Carlos São Carlos, São Paulo, Brazil.

Articles published in Obstet Gynecol Sci are open-access, distributed under the terms of the Creative Commons Attribution Non-Commercial License (http://creativecommons. org/licenses/by-nc/3.0/) which permits unrestricted non-commercial use, distribution, and reproduction in any medium, provided the original work is properly cited.

Copyright $\odot 2020$ Korean Society of Obstetrics and Gynecology 


\section{Obstetrics \& Gynecology Science}

Vol. 63, No. 5, 2020

these groups seemed to decrease with increasing age and time after birth $[4,5]$. Barbosa et al. [6] verified that 2 years after birth, the mode of delivery was not a risk factor for PFM dysfunction in primiparae women.

Parity itself has also been associated with an increased risk of PFM dysfunction $[2,4]$. However, most studies that investigated the function of these muscles and urinary symptoms after birth included nulliparae and primiparae women only [7-9]. Even though total global fecundity rates are decreasing, there is a need for studies that involve women who have experienced more than one pregnancy, considering that in most developed countries, this index is approximately 1.7 children per woman, and in developing countries, 4.2 children per woman [10].

Other factors that may affect long-term PFM function, such as constipation, urinary symptoms, and previous PFM training, have been scarcely investigated. Therefore, the primary aim of this study was to evaluate the long-term effect of parity on the function of the PFMs. The secondary objective was to investigate if any other variables, such as constipation, urinary symptoms, and previous PFM training during pregnancy, were associated with long-term PFM function. The hypothesis tested in this study was that women with 1 or 2 children would show greater impairment in PFM function than nulliparae women.

\section{Materials and methods}

This was a cross-sectional study completed at the Women's Health Research Laboratory (Laboratório de Pesquisa em Saúde da Mulher - LAMU) of the Federal University of São Carlos (Universidade Federal de São Carlos - UFSCar), São Carlos SP, Brazil, between August 2015 and August 2016.

Women were recruited in the city of São Carlos through flyer distribution, magazine and social network ads, referrals from public health units, and direct phone contact with women who sought out the laboratory due to their interest in evaluating their PFMs. The selected volunteers were nulliparae, primiparae, and secundiparae women. The parous volunteers had last given birth 1-6 years prior to the study. The exclusion criteria were neurological or cognitive dysfunctions that could impair the understanding of the proposed procedures, motor or neurological dysfunctions in the lower limbs, urinary tract or vaginal infections at the time of as- sessment, previous multiple pregnancies (twins, triplets, etc.), intolerance to vaginal palpation or manometry, and postmenopausal status.

An anamnesis was performed through an assessment form containing questions about maternal sociodemographic and anthropometric information - the body mass index was calculated from the information given by the woman regarding her weight and height, intestinal constipation-investigated using ROMA III criteria [11], urogynecologic and obstetric history, previous PFM training, and neonatal anthropometric information. In addition, the heights and weights of the volunteers were collected using a bioimpedance scale (Tanita IronMan ${ }^{\circledR}$ InnerScan BC-558). In order to verify current urinary symptoms, two questions from the King's Health Questionnaire (KHQ) [12] were asked: "Do you ever experience urinary urgency with urinary loss before reaching the toilet?" and "Do you ever experience urinary loss during physical efforts such as coughing, sneezing, running?" When urinary loss was confirmed, the full KHQ was applied. This questionnaire is composed of eight domains in which the score varies from 0 to 100, wherein the higher the score, the worse the quality of life [12]. Through the Baecke Habitual Physical Activity Questionnaire (BQHPA), the level of physical activity of the subjects in the last 12 months was evaluated [13].

The assessment of PFM function was performed by 2 experienced physical therapists using visual inspection, digital palpation, and manometry. Intraclass correlation coefficients (ICCS) were used to measure inter-rater reliability of the Modified Oxford Scale (ICC, 0.98) and manometry (ICC, $0.94)$. Two physiotherapy assessments were performed on 8 women within the same day, with a 15-minute interval between each assessment. Examiners were blind to each other's results and to the inter-rater reliabilities of the MOS (examiner A: ICC, 0.96; examiner B: ICC, 0.87).

The assessments were conducted with the volunteer in a supine position, hips and knees flexed, and feet flat on the stretcher. A visual inspection and a stress test were performed by simulating a cough, aiming to verify the presence of simultaneous PFM contraction, and to check for any loss of urine. Next, unidigital vaginal palpation was performed, in which the therapist introduced the index finger lubricated with gel approximately $4 \mathrm{~cm}$ into the vaginal canal. The volunteers were instructed to contract the PFM as hard as they could while minimally using the accessory musculature (abdominal, gluteal, and hip adductor musculature). The instruc- 


\section{Obstetrics \& Gynecology Science}

Daiane Munhoz Mira Bertacini, et al. The effect of parity on pelvic floor

tion was to achieve an "in and upward movement" to be able to the obtain the needed degree of contraction (referred to as "Power" in the PERFECT scheme) [14]. The contraction was classified according to the Modified Oxford Scale of the PERFECT scheme. Three PFM contractions were performed and only the highest value was counted. The other items of the PERFECT scheme ( $E=$ =endurance; $R=$ repetition; $F=$ fast)

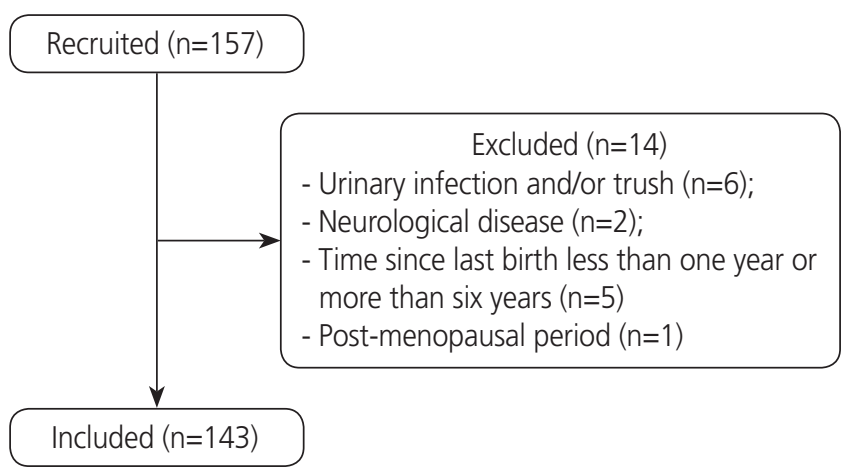

Fig. 1. The study flowchart. were also assessed. Although the Modified Oxford Scale may seem to be a subjective assessment method, it is 1 of the most widely used tools in clinical practice and scientific research, used to assess the function of PFM as part of the PERFECT scheme. This method presents satisfactory interrater reliability and validity, and a strong correlation with the contraction assessed by manometry in nulliparae women using Peritron equipment $[15,16]$.

Five minutes after completing digital palpation, the PFM contraction was assessed with Peritron (Cardio Design PtyLtd, Oakleigh, Victoria, Australia) equipment, and were graded from 0 to $300 \mathrm{cmH}_{2} \mathrm{O}$ and coupled to a vaginal probe $(28 \times 55 \mathrm{~mm})$. The probe was covered with a non-lubricated condom, with its center positioned $3.5 \mathrm{~cm}$ into the vaginal introitus - after which the vaginal resting pressure was collected [17]. The device was reset to 0 for each contraction, and the volunteer received verbal commands and motivation during the PFM contractions, each lasting 5 seconds. They were also instructed to achieve an "inward and upward

Table 1. Sociodemographic and anthropometric data and level of habitual physical activity of volunteers in three study groups

\begin{tabular}{|c|c|c|c|c|}
\hline Variables & NG $(n=40)$ & PG $(n=73)$ & SG $(n=30)$ & $P$-value \\
\hline Current age (yr) & $29.3 \pm 4.4$ & $32.4 \pm 4.5^{\mathrm{a})}$ & $37.0 \pm 4.8^{a, b)}$ & $<0.001$ \\
\hline Current BMI $\left(\mathrm{kg} / \mathrm{m}^{2}\right)$ & $23.8 \pm 3.1$ & $23.6 \pm 3.3^{a)}$ & $26.2 \pm 4.9^{\mathrm{a}, \mathrm{b})}$ & 0.011 \\
\hline \multicolumn{5}{|l|}{ BMI ranges } \\
\hline Low weight & $1(2.5)$ & $2(2.7)$ & 0 & \\
\hline Eutrophic & $27(67.5)$ & $50(68.5)$ & $14(46.7)$ & \\
\hline Overweight & $11(27.5)$ & $19(26.0)$ & $10(33.3)$ & 0.008 \\
\hline Obesity & $1(2.5)$ & $2(2.7)$ & $6(20.0)$ & \\
\hline Greatest lifetime body weight (kg) & $69.6 \pm 9.7$ & $75.9 \pm 10.2$ & $81.5 \pm 15.8$ & 0.061 \\
\hline BQHPA score & $8.1 \pm 1.3$ & $7.7 \pm 1.0$ & $8.1 \pm 1.3$ & 0.162 \\
\hline \multicolumn{5}{|l|}{ Ethnicity } \\
\hline White & $36(90.0)$ & $60(82.2)$ & $24(80.0)$ & \\
\hline Black & $2(5.0)$ & $2(2.7)$ & $2(6.7)$ & 0.684 \\
\hline Asian & 0 & $1(1.4)$ & $1(3.3)$ & \\
\hline Brown & $2(5.0)$ & $10(13.7)$ & $3(10.0)$ & \\
\hline \multicolumn{5}{|l|}{ Highest level of education } \\
\hline High school & 0 & $6(8.2)$ & $7(23.3)$ & \\
\hline Undergraduate degree & $7(17.5)$ & $8(11)$ & $3(10.0)$ & 0.154 \\
\hline Graduate degree & $33(82.5)$ & $59(80.8)$ & $20(66.7)$ & \\
\hline
\end{tabular}

Values are expressed as mean \pm standard deviation or number (\%).

NG, nulliparae group; PG, primiparae group; SG, secundiparae group; BMI, body mass index; BQHPA, Baecke Habitual Physical Activity Questionnaire.

a) $P \leq 0.05$ in relation to $\left.N G ;{ }^{b}\right) P \leq 0.05$ in relation to $P G$. 


\title{
Obstetrics \& Gynecology Science
}

\author{
Vol. 63, No. 5, 2020
}

movement" with maximal possible strength, while avoiding the activation of accessory muscles. The therapist visually confirmed the correct performance of the contractions by observing the movements of the probe, and by checking for minimal contractions of the accessory musculature [17]. Three contractions were performed with 1-minute intervals between them. In order to analyze the data, the mean value of the 3 contraction peaks was used. Vaginal manometry performed with Peritron equipment is considered to be a method with good intra-[18,19] and inter-reliability for the assessment of pelvic floor musculature [20].

The statistical analysis was performed using Statistica 7.0, and data normality was verified through a test of residuals. Next, the Kruskal-Wallis (for 3 groups) and Mann-Whitney tests (for 2 groups) were applied. The Fisher's exact test was performed to verify the association between qualitative variables and groups. A significance level of $5 \%$ was utilized. The sample calculation for this study was not performed at first, due to the lack of parameters in the literature on which to base calculations. A post hoc test was performed on the G*Power program using a 1-way analysis of variance with effect size 0.25 (small), 5\% error, and considering a sample of 140 volunteers. A power of 0.76 was obtained.

\section{Results}

For this study, 157 volunteers were recruited, 14 of whom were subsequently excluded (Fig. 1). The 143 volunteers included women who were grouped according to parity. There were 40 in nulliparae group (NG), 73 in primiparae group $(\mathrm{PG})$, and 30 in secundiparae (SG). Among the primiparae women, 36 (49.3\%) underwent a vaginal delivery, and 37 $(50.7 \%)$ underwent a cesarean section. Among the secundiparae women, 6 (20\%) had had 2 vaginal deliveries, 19 (63.3\%) had undergone 2 cesarean sections, and 5 (16.7\%) had had a vaginal delivery and a cesarean section. The mean time from the last delivery until the time of assessment was $2.5 \pm 1.5$ years for $P G$ and $3.7 \pm 1.7$ for $S G$ women (shown as mean and standard deviation) $(P<0.001)$.

Table 1 shows sociodemographic and anthropometric data from the subjects included in the study, as well as their level of habitual physical activity in the last 12 months (BQHPA Questionnaire). Their ages ranged from 21 to 48 years, body mass index (BMI) ranged from 16.9 to $38 \mathrm{~kg} / \mathrm{m}^{2}$, and the greatest body mass achieved during the women's lives ranged from 48 to $109 \mathrm{~kg}$.

PFM function assessed through the PERFECT scheme and manometry showed no significant difference in relation to

Table 2. The mean and standard deviation of PFM function assessed by the PERFECT scheme and manometry according to parity

\begin{tabular}{|c|c|c|c|c|}
\hline Variables & NG $(n=40)$ & PG $(n=73)$ & SG $(n=30)$ & $P$-value \\
\hline Power & $2.5 \pm 0.8$ & $2.3 \pm 0.9$ & $2.2 \pm 0.9$ & 0.482 \\
\hline Endurance & $3.4 \pm 2.3$ & $4.2 \pm 2.7$ & $3.3 \pm 1.7$ & 0.243 \\
\hline Repetition & $2.8 \pm 1.5$ & $2.8 \pm 2.0$ & $2.4 \pm 1.5$ & 0.172 \\
\hline Fast & $6.4 \pm 3.7$ & $6.0 \pm 3.2$ & $5.1 \pm 2.9$ & 0.391 \\
\hline Manometry $\left(\mathrm{cmH}_{2} \mathrm{O}\right)$ & $42.3 \pm 22.7$ & $35.0 \pm 21.8$ & $33.2 \pm 20.0$ & 0.144 \\
\hline
\end{tabular}

Values are expressed as mean mean \pm standard deviation (\%).

NG, nulliparae group; SG, secundiparae group; PG, primiparae group.

Table 3. Occurrence of intestinal constipation, presence of current UI, and previous pelvic floor muscle training

\begin{tabular}{|c|c|c|c|c|}
\hline Variables & NG $(n=40)$ & PG $(n=73)$ & SG $(n=30)$ & $P$-value \\
\hline Constipation & $4(10.0)$ & $9(12.3)$ & $2(6.7)$ & 0.542 \\
\hline Urge urinary incontinence & $1(2.5)$ & $9(12.3)$ & $1(3.5)$ & 0.100 \\
\hline Stress urinary incontinence & $7(17.5)$ & $14(19.2)$ & $10(33.3)$ & 0.212 \\
\hline Previous training of the pelvic floor muscles & $6(15.0)$ & $22(30.1)$ & $5(16.7)$ & 0.120 \\
\hline
\end{tabular}

Values are expressed as number (\%).

NG, nulliparae group; PG, primiparae group; SG, secundiparae group. 


\section{Obstetrics \& Gynecology Science}

Daiane Munhoz Mira Bertacini, et al. The effect of parity on pelvic floor

parity, as shown in Table 2. Nineteen volunteers (47.5\%) from the NG group, 29 (39.7\%) from the PG group, and 10 (53.3\%) from SG group ( $P=0.572)$ presented contraction grades of 3 or 4 on the Modified Oxford Scale.

Data regarding intestinal constipation, pelvic floor muscle training, and the presence of current $\mathrm{UI}$ is shown in Table 3. There was no significant difference in KHQ domains among groups. The "UI impact" domain presented high scores in all the groups, averaging $57.1 \pm 41.7$ in the NG group, $40.5 \pm 32.5$ in the PG group, and 38.1 \pm 12.6 in the SG group (shown as mean and standard deviation) ( $P=0.501)$.

Table 4 presents information about pregnancy. There were significant differences in maternal age at the beginning of pregnancy among groups, with maternal age being higher in the SG group $(P<0.001)$. In contrast, PFM preparation for birth was higher in the $P G$ group $(P=0.022)$.

Obstetric data, which were directly dependent on the volunteers' memories, were collected. At the time of the last birth, 7 (6.8\%) women reported having undergone episiotomy, with 3 (4.1\%) from the PG group and 4 (13.3\%) from the SG group. Thirty-one (30.1\%) women reported having some degree of perineal tearing, 26 (35.6\%) from the PG group and 5 (16.7\%) from the SG group.

Neonatal data were collected from their children's health booklets. The mean body mass of the biggest newborn from the $P G$ group was $3.3 \pm 0.5 \mathrm{~kg}$, and it was $3.5 \pm 0.6 \mathrm{~kg}$ in the $\mathrm{SG}$ group (shown as mean and standard deviation) $(P=0.243)$. The mean head circumference in the $P G$ group was $33.5 \pm 1.7 \mathrm{~cm}$, and it was $35.6 \pm 4.7 \mathrm{~cm}$ in the $S G$ group (shown as mean and standard deviation) ( $P=0.112$ ). There was no significant difference between groups for both variables analyzed.

No correlation was found among the age at the time of assessment and BMI, parity, time between last birth and assessment, level of physical activity (BQHPA score), UI severity measure (KHQ score), maternal age and body mass at the beginning of last pregnancy, body mass gain during first and second pregnancies, neonatal data (body mass, length and head circumference), and PFM function as assessed through the P ("Power") item of the PERFECT scheme and vaginal manometry.

\section{Discussion}

The present study could verify that PFM function was similar among the nulliparae, primiparae, and secundiparae groups. Studies have shown that regardless of parity and mode of birth, there could be a decrease in PFM function after pregnancy. Nonetheless, the musculature has the capacity to recover its contractility up until 1 year after birth [21-23].

Normal PFM function has been described as the capacity to perform a contraction around the pelvic orifices, with an inward and upward movement of the perineum $[24,25]$. Less than half of the volunteers in the present study were able to perform a contraction graded 3 or 4 according to the Modified Oxford Scale. With regards to vaginal manometry, there are no minimum recommended values. However, our study showed a higher absolute mean manometry value in the nulliparae group, but there was no significant difference when compared to the other groups. This may be due to the large standard deviation observed in the values of manometry for all groups, which could be explained by the difficulty in performing a PFM contraction correctly. According to the literature, approximately $30 \%$ of women cannot contract these muscles properly [26]. Furthermore, only a few women reported having performed any kind of training for the pelvic floor muscles, and they were mainly nulliparae. Training for the pelvic floor muscles has been recommended during

Table 4. Information about the gestational period, urinary symptoms, and PFM preparation for birth

\begin{tabular}{|c|c|c|c|}
\hline Variables & PG $(n=73)$ & SG $(n=30)$ & $P$-value \\
\hline Maternal age at the beginning of last pregnancy (yr) & $29.6 \pm 4.3$ & $32.9 \pm 4.2$ & $<0.001$ \\
\hline Body mass gain in last pregnancy $(\mathrm{kg})$ & $13.1 \pm 5.2$ & $12.2 \pm 4.6$ & 0.622 \\
\hline Urge urinary incontinence during pregnancy & $12(16.4)$ & $3(10.0)$ & 0.402 \\
\hline Stress urinary incontinence during pregnancy & $23(31.5)$ & $9(30.0)$ & 0.881 \\
\hline Pelvic floor musculature training during pregnancy & $35(47.9)$ & $8(26.7)$ & 0.022 \\
\hline
\end{tabular}

Values are expressed as mean \pm standard deviation or number (\%).

PFM, pelvic floor muscle; PG, primiparae group; SG, secundiparae group. 


\section{Obstetrics \& Gynecology Science}

Vol. 63, No. 5, 2020

pregnancy and after birth, to strengthen the PFM, contribute to its recovery, and prevent future dysfunctions such as $\mathrm{UI}$ $[27,28]$.

Pregnancy itself can be considered a risk factor for alterations in PFM function and a contributor to the occurrence of urinary symptoms resulting from the hormonal, anatomical, and functional modifications in the urinary tract during this period [1]. Other studies have demonstrated that the second pregnancy and delivery do not influence the structure and function of the pelvic floor. Rather, the first birth is a major contributor predisposing women to greater pelvic floor impairments [29,30]. In contrast, Jundt et al. [30] verified that secundiparae women had significantly poorer PFM function than primiparae women 27 months after birth, but there was no difference in the presence of $\mathrm{UI}$ and bladder neck hypermobility between the groups. Özdemır et al. [31] also demonstrated that PFM function, assessed through vaginal manometry, decreases with the increase in parity.

In the present study, both women that have had a vaginal and/or cesarean delivery were placed together in the PG and SG groups. During vaginal delivery, there may be compression and stretching of the neural, muscular, and connective structures, contributing to the changes in PFM function after birth [32]. Friedman et al. [33] found that vaginal and forceps deliveries were associated with a greater impairment in PFM function in multiparous women, 6 to 11 years postpartum. Driusso et al. [34] found through a systematic review that there was no difference in short-term PFM strength after childbirth between primiparae women who underwent cesarean section and those who underwent vaginal delivery. The difference in the results reported by the studies may be explained by the chosen assessment method, period after birth in which the assessment was conducted [27], classification adopted in studies referring to the type of birth, utilization of unwanted instruments and interventions (such as forceps, vacuum, Kristeller maneuver, and episiotomy), and the lack of standardization for PFM function classification parameters.

A few studies investigated other factors associated with the impairment of PFM function in a period considered long term after birth. In the present study, neonatal, sociodemographic, and anthropometric data were similar among groups. There were differences in current maternal age and BMI, maternal age at the beginning of the last pregnancy, and the performance of physical therapy techniques to prepare the PFM for birth among groups. The SG group had higher greater maternal age and $\mathrm{BMI}$ and had fewer members who underwent PFM preparation for birth; however, these factors do not influence long-term PFM function. Bocardi et al. [35] showed that aging is not a determinant of reduced function and electromyographic activity of the pelvic floor musculature. In the short term, Mendes et al. [27] verified that maternal age, marital status, ethnicity, and newborn body mass did not influence the PFM function in primiparae women, 50 to 70 days postpartum. It is thus expected that further studies on the influence of these factors on PFM function would not find associations, although these data should still be collected.

UI can lead to a reduction in a woman's quality of life [2]. Valeton and do Amaral [3] found a reduction in the quality of life related to UI symptoms and the domains assessed through KHQ after birth. In the current study, there was no explicit difference among groups in terms of impairment in the quality of life, with UI complaints assessed by the domains of the KHQ questionnaire. However, the domain that presented a higher absolute score was "Incontinence Impact." In addition, in terms of UI during pregnancy and current UI, no significant difference was found among groups. Fritel et al. [28] reported that the risk factors for UI are multifactorial, but that the second birth did not increase the risk of SUI. Other studies imply that parity is a risk factor for UI $[2,4]$. Rortveit et al. [36] verified, through a questionnaire, an association among parity, SUI, and mixed UI among women aged less than 65 years. Additionally, they found a high prevalence of $\mathrm{UI}$ among nulliparae women, indicating that other risk factors may be related to this dysfunction [36]. The type of birth has also been found to be associated with $\mathrm{UI}$, with studies suggesting that vaginal delivery increases the long-term risk of UI after birth when compared with cesarean delivery [4]. Nevertheless, Qian et al. [37] demonstrated through questionnaires that cesarean surgery does not confer long-term protection against SUI after birth. Furthermore, women who presented with UI during pregnancy or puerperium had a higher long-term risk of symptom occurrence [30]. Since the present study did not find an association between parity and UI, with prior research being controversial and implicating a multifactorial explanation for UI, these results may help improve quality of life for the population with UI by providing evidence that can lead to the identification of possible risk factors. 


\section{Obstetrics \& Gynecology Science}

Daiane Munhoz Mira Bertacini, et al. The effect of parity on pelvic floor

Additionally, current prospective studies involving the assessment of function before and during pregnancy, with long-term follow-up after birth, may contribute to the elucidation of the factors associated with PFM function impairment.

Our study had some limitations, such as the smaller number of women in the secundiparae group. A larger sample for this specific group may have allowed for a better analysis of the influence of the variables affecting PFM function. Another limitation was that the obstetric and intervention data depended on maternal memory, which could have influenced the accuracy of this information. However, it is worth emphasizing that our study included the use of validated questionnaires and instruments, standardization of subjective assessments and high reliability between examiners conducting such assessments, careful collection of data on time elapsed since the last delivery and the time of assessment, and the inclusion of secundiparae women.

In conclusion, parity was not found to have any effect on long-term PFM function and urinary symptoms, such as UI, after birth, regardless of the mode of delivery.

\section{Acknowledgements}

This study was financed in part by the Coordenação de Aperfeiçoamento de Pessoal de Nível Superior - Brasil (CAPES) - Finance Code 001 and National Council for Scientific and Technological Development (CNPq), process number: 131169/2016-5.

\section{Conflict of interest}

No potential conflict of interest relevant to this article was reported.

\section{Ethical approval}

This study was approved by the Research Ethics Committee of the Federal University of São Carlos (resolution 1.034.342).

\section{Patient consent}

All volunteers were informed about the proposed procedures, and those who agreed to participate voluntarily signed an informed consent form.

\section{References}

1. Sangsawang B. Risk factors for the development of stress urinary incontinence during pregnancy in primigravidae: a review of the literature. Eur J Obstet Gynecol Reprod Biol 2014;178:27-34.

2. Balik G, Güven ES, Tekin YB, Şentürk Ş, Kağitci M, Üstüner I, et al. Lower urinary tract symptoms and urinary incontinence during pregnancy. Low Urin Tract Symptoms 2016;8:120-4.

3. Valeton CT, do Amaral VF. Evaluation of urinary incontinence in pregnancy and postpartum in Curitiba Mothers Program: a prospective study. Int Urogynecol J Pelvic Floor Dysfunct 2011;22:813-8.

4. Tähtinen RM, Cartwright R, Tsui JF, Aaltonen RL, Aoki Y, Cárdenas $J \mathrm{~L}$, et al. Long-term impact of mode of delivery on stress urinary incontinence and urgency urinary incontinence: a systematic review and meta-analysis. Eur Urol 2016;70:148-58.

5. Hallock JL, Handa VL. The epidemiology of pelvic floor disorders and childbirth: an update. Obstet Gynecol Clin North Am 2016;43:1-13.

6. Barbosa AM, Marini G, Piculo F, Rudge CV, Calderon IM, Rudge MV. Prevalence of urinary incontinence and pelvic floor muscle dysfunction in primiparae two years after cesarean section: cross-sectional study. Sao Paulo Med J 2013;13:9-95.

7. Barbosa AMP, Carvalho LR, Martins AMVC, Calderon IMP, Rudge MVC. The influence of the delivery route on pelvic floor muscle strength. Rev Bras Ginecol Obstet 2005;27:677-82.

8. Gameiro MO, Sousa VO, Gameiro LF, Muchailh RC, Padovani CR, Amaro JL. Comparison of pelvic floor muscle strength evaluations in nulliparous and primiparous women: a prospective study. Clinics (Sao Paulo) 2011;66:1389-94.

9. Hilde G, Stær-Jensen J, Siafarikas F, Engh ME, Brækken $I H, B \varnothing K$. Impact of childbirth and mode of de- 


\section{Obstetrics \& Gynecology Science}

Vol. 63, No. 5, 2020

livery on vaginal resting pressure and on pelvic floor muscle strength and endurance. Am J Obstet Gynecol 2013;208:50.e1-7.

10. Population Division, Department of Economic and Social Affairs of the United Nations Secretariat. World population prospects: the 2010 revision. New York (NY): United Nations; 2011.

11. World Gastroenterology Organization (WGO). World Gastroenterology Organization practice guidelines. Constipation: a global perspective. Milwaukee (WI): World Gastroenterology Organization; 2010.

12. Tamanini JT, D'Ancona CA, Botega NJ, Rodrigues Netto $\mathrm{N}$ Jr. Validation of the Portuguese version of the King's Health Questionnaire for urinary incontinent women. Rev Saude Publica 2003;37:203-11.

13. Garcia LMT, Osti RFI, Ribeiro EHC, Florindo AA. Validation of two questionnaires to assess physical activity in adults. Rev Bras Ativ Fis Saude 2013;18:317-31.

14. Laycock J, Jerwood D. Pelvic floor muscle assessment: the PERFECT scheme. Physiotherapy 2001;87:631-42.

15. Bø K, Finckenhagen HB. Vaginal palpation of pelvic floor muscle strength: inter-test reproducibility and comparison between palpation and vaginal squeeze pressure. Acta Obstet Gynecol Scand 2001;80:883-7.

16. Pereira VS, Hirakawa HS, Oliveira AB, Driusso P. Relationship among vaginal palpation, vaginal squeeze pressure, electromyographic and ultrasonographic variables of female pelvic floor muscles. Braz J Phys Ther 2014;18:42834.

17. Ferreira $C H$, Barbosa PB, de Oliveira Souza F, Antônio $\mathrm{Fl}$, Franco MM, Bø K. Inter-rater reliability study of the modified Oxford Grading Scale and the Peritron manometer. Physiotherapy 2011;97:132-8.

18. Rahmani N, Mohseni-Bandpei MA. Application of perineometer in the assessment of pelvic floor muscle strength and endurance: a reliability study. J Bodyw Mov Ther 2011;15:209-14.

19. Frawley HC, Galea MP, Phillips BA, Sherburn M, Bø K. Reliability of pelvic floor muscle strength assessment using different test positions and tools. Neurourol Urodyn 2006;25:236-42.

20. Ribeiro JS, Guirro EC, Franco MM, Duarte TB, Pomini JM, Ferreira $\mathrm{CH}$. Inter-rater reliability study of the Peritron ${ }^{\mathrm{TM}}$ perineometer in pregnant women. Physiother Theory Pract 2016;32:209-17.
21. Elenskaia K, Thakar R, Sultan AH, Scheer I, Beggs A. The effect of pregnancy and childbirth on pelvic floor muscle function. Int Urogynecol J Pelvic Floor Dysfunct 2011;22:1421-7.

22. Li W, Li Y. Effect of pelvic floor muscle training on the pelvic floor muscle tônus. J Chin Clin Med 2009;8:4358.

23. Barbosa AM, Dias A, Marini G, Calderon IM, Witkin S, Rudge MV. Urinary incontinence and vaginal squeeze pressure two years post-cesarean delivery in primiparous women with previous gestational diabetes mellitus. Clinics (Sao Paulo) 2011;66:1341-6.

24. Talasz H, Himmer-Perschak G, Marth E, Fischer-Colbrie J, Hoefner E, Lechleitner M. Evaluation of pelvic floor muscle function in a random group of adult women in Austria. Int Urogynecol J Pelvic Floor Dysfunct 2008;19:1315.

25. Kegel AH. Progressive resistance exercise in the functional restoration of the perineal muscles. Am J Obstet Gynecol 1948;56:238-48.

26. Bø K, Sherburn M. Evaluation of female pelvic-floor muscle function and strength. Phys Ther 2005;85:26982.

27. Mendes EP, Oliveira SM, Caroci AS, Francisco AA, Oliveira SG, Silva RL. Pelvic floor muscle strength in primiparous women according to the delivery type: cross-sectional study. Rev Lat Am Enfermagem 2016;24:e2758.

28. Fritel X, Fauconnier A, Levet C, Bénifla JL. Stress urinary incontinence 4 years after the first delivery: a retrospective cohort survey. Acta Obstet Gynecol Scand 2004;83:941-5.

29. Horak TA, Guzman-Rojas RA, Shek KL, Dietz HP. Pelvic floor trauma: does the second baby matter? Ultrasound Obstet Gynecol 2014;44:90-4.

30. Jundt K, Scheer I, von Bodungen V, Krumbachner F, Friese $K$, Peschers UM. What harm does a second delivery to the pelvic floor? Eur J Med Res 2010;15:362-6.

31. Özdemı ÖÇ, Bakar Y, Özengın N, Duran B. The effect of parity on pelvic floor muscle strength and quality of life in women with urinary incontinence: a cross sectional study. J Phys Ther Sci 2015;27:2133-7.

32. Hilde G, Bo K. The pelvic floor during pregnancy and after childbirth, and the effect of pelvic floor muscle training on urinary incontinence - a literature review. Curr Womens Health Rev 2015;11:19-30. 


\section{Obstetrics \& Gynecology Science}

Daiane Munhoz Mira Bertacini, et al. The effect of parity on pelvic floor

33. Friedman S, Blomquist JL, Nugent JM, McDermott KC, Muñoz A, Handa VL. Pelvic muscle strength after childbirth. Obstet Gynecol 2012;120:1021-8.

34. Driusso P, Beleza ACS, Mira DM, de Oliveira Sato T, de Carvalho Cavalli R, Ferreira CHJ, et al. Are there differences in short-term pelvic floor muscle function after cesarean section or vaginal delivery in primiparous women? A systematic review with meta-analysis. Int Urogynecol J. Forthcoming 2020.

35. Bocardi DA, Pereira-Baldon VS, Ferreira CH, Avila MA,
Beleza AC, Driusso P. Pelvic floor muscle function and EMG in nulliparous women of different ages: a crosssectional study. Climacteric 2018;21:462-6.

36. Rortveit G, Hannestad YS, Daltveit AK, Hunskaar S. Ageand type-dependent effects of parity on urinary incontinence: the Norwegian EPINCONT study. Obstet Gynecol 2001;98:1004-10.

37. Qian R, Chen Z, Tang L, Zhang W. Postpartum adverse effects and sexual satisfaction following cesarean delivery in Beijing. Int J Gynaecol Obstet 2016;132:200-5. 